\title{
Ancient DNA comes of age, but still has some
}

AUTHOR:

Alan G. Morris ${ }^{1}$

\section{AFFILIATION:}

'Department of Human Biology, University of Cape Town, Cape Town, South Africa

\section{CORRESPONDENCE TO: Alan Morris}

EMAIL:

alan.morris@uct.ac.za

\section{KEYWORDS:}

South African archaeological sites; fossil DNA

\section{HOW TO CITE:}

Morris A. Ancient DNA comes of age, but still has some teenage problems. S Afr J Sci. 2017;113(9/10), Art. \#a0232, 2 pages. http://dx.doi. org/10.17159/sajs.2017/a0232
In 2015, I wrote an opinion piece ${ }^{1}$ in this journal announcing the successful extraction of a mitochondrial DNA (mtDNA) sequence from a 2300-year-old skeleton from Saldanha Bay, South Africa². My concluding passage noted that the latest research was focused on nuclear autosomal DNA to provide data on admixture between populations and the impact of natural selection on specific genetic traits and that we could expect publication of articles on this topic in the near future.

Well, I was not far off. A few months later, a paper was published in Nature presenting the genome of a 4500 -yearold individual from Mota Cave in Ethiopia. ${ }^{3}$ The actual analysis was excellent, but there were problems in the comparative data ${ }^{4}$ and one of the conclusions of the paper - that of a backflow of Eurasian ancestry affecting much of western and central Africa around three millennia ago - was subsequently rejected. The error was as a result of incompatible software in the analysis of genetic sequences from different comparative samples, which did not detract at all from the actual gene sequence retrieved. The Mota project was one of several happening on a range of ancient African DNA samples. A year earlier, Molebogeng Bodiba from the University of Pretoria was working at a lab in Zurich on South African samples from Early and Late Iron Age sites. ${ }^{5}$ Unfortunately she has been unable to generate full mitochondrial sequences from her specimens, but she indeed has been the first to produce at least partial mtDNA data on Iron Age samples. As I mentioned in the 2015 paper, a small group of us at the University of Cape Town, in collaboration with the lab in Leipzig, has been working on samples from the Later Stone site of Faraoskop in the Western Cape, to find both mitochondrial and nuclear DNA samples and we are on the cusp of publication. Other Later Stone Age samples have been obtained from specimens in the Iziko Museums and are being analysed in Copenhagen by a different team; and most recently has been the report on three Later Stone Age foragers and four Iron Age individuals from Natal analysed in Uppsala, Sweden. ${ }^{6}$

Just to add to the mix are two studies from north of our border. Sloan Williams and Ryan Raaum ${ }^{7}$ have extracted mtDNA sequences in a lab in Chicago from 38 individuals from the Swahili coast. The site of Mtwapa was a major Swahili town from the 9th to the 18th centuries, and the burials dating from the 17th century represent the largest sample of ancient DNA from a single site in Africa. This study is going to give us a wonderful insight into the biodynamics of a single population in the African past. Another team associated with David Reich's lab in Boston has extracted genomic DNA from several individuals from Tanzania, including an ancient skeleton from the islands of Zanzibar. And further to the west are two projects centred on Malawi and Zambia, looking at both Iron Age and Later Stone Age samples. The two studies are using different laboratories - one in Boston and the other in Uppsala. The Malawi project has successfully extracted full genomic DNA from a number of Later Stone Age specimens going back some 4000 years. ${ }^{8}$

This hive of African DNA analysis does not even include a wider range of research on the genetic lineages of living African peoples in search of the elusive point of divergence of our ancestors from the Neanderthals and other archaic populations and the subsequent divergence of populations in Africa. ${ }^{9-14}$

But there are problems. This rush to extract the secrets of ancient DNA in Africa has presented the curators of the collections of archaeological skeletons with ethical issues because the research requires the destruction of human bone. I have identified four central problems that concern me and that have been echoed in my private correspondence with various colleagues: competition between labs for samples; the danger of parachute research; the divorce between bioarchaeology and genetics; and laboratory methodologies and comparative data.

\section{Competition between labs for samples}

Competition for samples has become a very real problem. There are at least five labs that have been processing archaeological skeletons from South Africa. Back in May 2014, I made a list of all ancient DNA projects on South African specimens that had, up to that point, been proposed or were in action. I counted 13. Not all of these projects have taken place. In some cases permission to sample has been refused. The Department of Human Biology at the University of Cape Town, the Iziko Museums and the School of Anatomical Sciences at the University of the Witwatersrand all have elaborate procedures that must be followed before their respective osteological curators will grant permission to sample. In every case the science involved in the project (and the hypothesis it wishes to test) is required to meet an exacting standard. In the case of lziko Museums there must also be a clear-cut benefit to descendant communities. One reason for refusal is that the project is simply an attempt to analyse skeletons because they are old and available. This may be good for the laboratory concerned, but it is just plain bad science and is perilously close to 'mining' of bone specimens from museums. In the case of very old specimens, such as Middle Stone Age material, the curating institutions have requested that associated animal bone is processed first and permission to analyse the human remains will only be granted if the animal specimens produce results. In addition, an export permit is required from the South African Heritage Resources Agency before any specimen is sent out of the country to a foreign laboratory.

\section{The danger of 'parachute research'}

Sampling in this kind of research is very easy to do. All that is required is a nubbin of bone and once the sample actually leaves the country, all of the analysis happens elsewhere. So how should South African researchers fit in? There has been an attempt to train young South Africans to work with ancient DNA and I am aware of students who have been sent to labs in Leipzig (Germany), Zurich (Switzerland) and Phoenix (Arizona, USA), but there are not as 
yet any jobs for those who have qualified. For a number of years there was an active resistance to setting up a South African lab in the belief that it was too expensive and funding would be better spent on projects that have a more direct benefit to the previously disadvantaged people of the country. That attitude is now changing in some quarters and I have heard talk of setting up labs in Cape Town, Johannesburg and Pretoria. How would such labs link to overseas institutions?

\section{The divorce between bioarchaeology and genetics}

There has been a definite tendency for genetic research to ignore information from osteologically based previous research. ${ }^{15}$ Until very recently, whether the data were Y-chromosome, mitochondrial or autosomal DNA, the search has been for lineage and the presence of an actual skeleton has been irrelevant. All that has been required is a tiny fragment of bone that can yield DNA, but can such studies give us a true picture of the past? The answer is 'yes' in terms of lineage, but ' $n o$ ' in terms of life experience and adaptation.

This issue is indeed important because the first choice in sampling should be that from as complete a skeleton as possible so that we can compare genetic and osteological data. Perhaps the most extreme example of this problem is the construction of the human ancestor known as the 'Denisovans'. ${ }^{16}$ Much has been written about the genetics of these distant ancestors, but all of it has been based on one finger bone and three teeth from one site. We actually know nothing about these people except for their genetic shadow. The forensic anthropologist in me screams that I must have a body before making any conclusions. The same goes for the discussion of people from the comparatively recent African past.

\section{Laboratory methodologies and comparative data}

As a non-geneticist, it did not cross my mind that different labs might produce different DNA results. Some years ago I had my own Y-chromosome and mtDNA analysed. The results were fascinating, but I was extremely surprised to discover that if I sent the same samples to different DNA heritage laboratories I could get different results. It is not the analysis itself that is different, but the reference samples that are chosen for comparison. Clearly this kind of problem can be resolved as the analysed samples become more numerous (as long as the different labs share their results), but I have recently discovered that not all labs are the same when it comes to long sequence autosomal DNA. The processing methods are not interchangeable and there are at least two different methodologies that produce different success rates and differing levels of data volume. How do we resolve this? One possibility suggested by an anthropological genetics colleague is to allow for multiple samples to be taken from the same individual. Basically we are saying double the destructive sample size. That would not be popular, but a new technique has just been published ${ }^{17}$ that utilises a miniscule core boring of bone. Double sampling would not be such a tender point with such new methodology.

Where do we go from here? How do we resolve these problems? Much of the competition is publication driven with labs chasing the next Nature paper. I cannot overestimate the power of high-impact journal publications in generating funds for laboratories, or promotions for their denizens. But the result is that very little is ublished in African accessible journals. Where are the papers that engage the African scientists in the developing countries to the north of our border? The research results from the study of ancient DNA directly involve the descendant communities living in the countries from which the archaeological samples are extracted. And even when the populations being studied are extinct, the story of their presence is part of the heritage of all of the people who live there now.

\section{Acknowledgement}

Alan Morris is supported by an Incentive Grant from the National Research Foundation of South Africa.

\section{References}

1. Morris AG. Ancient DNA comes of age. S Afr J Sci. 2015;111(5/6), Art. \#a0108, 2 pages. https://doi.org/10.17159/sajs.2015/a0108

2. Morris AG, Heinze A, Chan E, Smith AB, Hayes VM. First ancient mitochondrial human genome from a pre-pastoralist southern African. Genome Biol Evol. 2014:6(10):2647-2653. https://doi.org/10.1093/gbe/evu202

3. Llorente MG, Jones ER, Eriksson A, Siska V, Arthur KW, Arthur JW, et al. Ancient Ethiopian genome reveals extensive Eurasian admixture in Eastern Africa. Science. 2015;350:820-822. https://doi.org/10.1126/science. aad2879

4. Callaway E. Error found in study of first ancient African genome. Nature News. 2016 January 29. https://doi.org/10.1038/nature.2016.19258

5. Bodiba M. Ancient DNA analysis of the Thulamela remains: Deciphering the migratory patterns of a southern African human population [MSc thesis]. Pretoria: University of Pretoria; 2014.

6. Schlebusch CM, Malmström H, Günther T, Sjödin P, Coutinho A, Edlund H, et al. Ancient genomes from southern Africa pushes modern human divergence beyond 1260,000 years ago [bioRxiv preprint 145409]. c2017 [cited 2017 Aug 24]. http://dx.doi.org/10.1101/145409

7. Raaum R, Williams SR, Kusimba C, Monge J, Morris AG, Mohamed MM Decoding the Swahili: The genetic ancestry of the Swahili. In: WynneJones S, LaViolette A, editors. The Swahili world. Oxford: Taylor \& Francis/ Routledge. In press 2017.

8. Skoglund P, Thompson JC, Prendergast ME, Mittnik A, Sirak K, Hajdinjak M, et al. Reconstructing prehistoric African population structure. Cell. 2017;131, Art. \#9774, 13 pages. http://dx.doi.org/10.1016/j.cell.2017.08.049

9. Barbieri C, Güldemann T, Naumann C, Gerlach L, Berthold F, Nakagawa H, et al. Unraveling the complex maternal history of southern African Khoisan populations. Am J Phys Anthropol. 2014;153:435-448. https://doi. org/10.1002/ajpa.22441

10. Barbieri C, Hübner A, Macholdt E, Ni S, Lippold S, Schröder R, et al. Refining the $Y$ chromosome phylogeny with southern African sequences. Hum Genet. 2016;135:541-553. https://doi.org/10.1007/s00439-016-1651-0

11. Chan EKF, Hardie R-A, Petersen DC, Beeson K, Bornman RMS, Smith AB, et al. Revised timeline and distribution of the earliest diverged human maternal lineages in southern Africa. PLOS ONE. 2015;10(3), e0121223, 17 pages https://doi.org/10.1371/journal.pone.0121223

12. Chimusa ER, Meintjies A, Tchanga M, Mulder N, Seioghe C, Soodyall H, et al. A genomic portrait of haplotype diversity and signatures of selection in indigenous southern African populations. PLoS Genet. 2015;11(3), e1005052, 28 pages. https://doi.org/10.1371/journal.pgen.1005052

13. Mallick S, Li H, Lipson M, Mathieson I, Gymrek M, Racimo R, et al. The Simons Genome Diversity Project: 300 genomes from 142 diverse populations. Nature. 2016;538:201-206. https://doi.org/10.1038/nature18964

14. Schlebusch CM, Prins F, Lombard M, Jakobsson M, Soodyall H. The disappearing San of southeastern Africa and their genetic affinities. Hum Genet. 2016;135:1365-1373. https://doi.org/10.1007/s00439-016-1729-8

15. Morris AG. Prehistory in blood and bone: An essay on the reconstruction of the past from genetics and morphology. Trans Roy Soc S Afr. 2005;60(2):111114. https://doi.org/10.1080/00359190509520487

16. Reich D, Green RE, Kircher M, Krause J, Patterson N, Durand EY, et al. Genetic history of an archaic hominin group from Denisova Cave in Siberia. Nature. 2010;468:1053-1060. https://doi.org/10.1038/nature09710

17. Sirak K, Novak M, Cheronet 0 . A minimally-invasive method for sampling human petrous bones from the cranial base for ancient DNA analysis. BioTechniques. 2017;62(6):283-289. https://doi.org/10.2144/000114558 